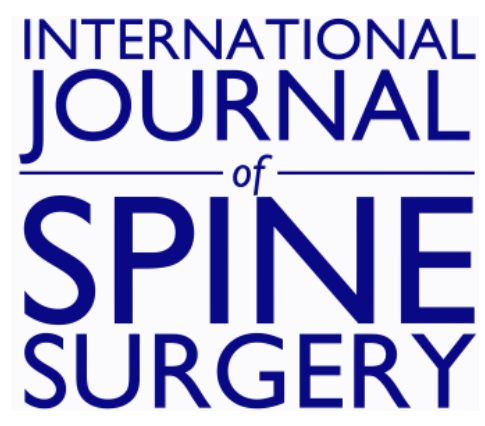

\title{
Cervical Spine Trauma in East Africa: Presentation, Treatment, and Mortality
}

Scott L. Zuckerman, Arsalan Haghdel, Noah L. Lessing, Joseph Carnevale, Beverly Cheserem, Albert Lazaro, Andreas Leidinger, Nicephorus Rutabasibwa, Hamisi K. Shabani, Halinder Mangat and Roger Härtl

Int J Spine Surg published online 22 September 2021

http://ijssurgery.com/content/early/2021/09/20/8113

This information is current as of April 25, 2023.

Email Alerts Receive free email-alerts when new articles cite this article. Sign up at:

http://ijssurgery.com/alerts

The International Journal of Spine Surgery

2397 Waterbury Circle, Suite 1,

Aurora, IL 60504, Phone: +1-630-375-1432 


\title{
Cervical Spine Trauma in East Africa: Presentation, Treatment, and Mortality
}

\author{
SCOTT L. ZUCKERMAN, MD, MPH, ${ }^{1,2}$ ARSALAN HAGHDEL, MPH, ${ }^{1}$ NOAH L. LESSING, BS, ${ }^{3}$ \\ JOSEPH CARNEVALE, MD ${ }^{1}$ BEVERLY CHESEREM, FRCS NEUROSURGERY, ${ }^{1}$ ALBERT LAZARO, MD ${ }^{4}$ \\ ANDREAS LEIDINGER, MD ${ }^{5}$ NICEPHORUS RUTABASIBWA, MD,${ }^{4}$ HAMISI K. SHABANI, MD, PHD, ${ }^{4}$ \\ HALINDER MANGAT, MD, ${ }^{1}$ ROGER HÄRTL, MD ${ }^{1}$ \\ ${ }^{l}$ Weill Cornell Brain and Spine Center, New York-Presbyterian Hospital, Weill Cornell Medical College, New York, New York, ${ }^{2}$ Vanderbilt Department of \\ Neurosurgery, Vanderbilt University Medical Center, Nashville, Tennessee, ${ }^{3}$ University of Maryland School of Medicine, Baltimore, Maryland, ${ }^{4}$ Muhimbili \\ Orthopedic Institute, Dar es Salaam, Tanzania, ${ }^{5}$ Department of Neurosurgery, Hospital General de Catalunya, Sant Cugat, Spain
}

\begin{abstract}
Background: Cervical spine trauma (CST) leads to devastating neurologic injuries. In a cohort of CST patients from a major East Africa referral center, we sought to $(a)$ describe presentation and operative treatment patterns, $(b)$ report predictors of neurologic improvement, and $(c)$ assess predictors of mortality.

Methods: A retrospective, cohort study of CST patients presenting to a tertiary hospital in Dar Es Salaam, Tanzania, was performed. Demographic, injury, and operative data were collected. Neurologic exam on admission/ discharge and in-hospital mortality were recorded. Univariate/multivariate logistic regression assessed predictors of operative treatment, neurologic improvement, and mortality.

Results: Of 101 patients with CST, $25(24.8 \%)$ were treated operatively on a median postadmission day $16.0(7.0-$ 25.0). Twenty-six patients $(25.7 \%)$ died, with $3(12.0 \%)$ in the operative cohort and $23(30.3 \%)$ in the nonoperative cohort. The most common fracture pattern was bilateral facet dislocation (26.7\%). Posterior cervical laminectomy and fusion and anterior cervical corpectomy were the 2 most common procedures. Undergoing surgery was associated with an injury at the $\mathrm{C} 4-\mathrm{C} 7$ region versus occiput-C3 region (odds ratio [OR] 6.36, 95\% confidence interval [CI] 1.71-32.28, $P=.011)$ and an incomplete injury (OR 3.64; 95\% CI 1.19-12.25; $P=.029)$. Twelve patients $(15.8 \%)$ improved neurologically, out of the 76 total patients with a recorded discharge exam. Having a complete injury was associated with increased odds of mortality (OR 11.75, 95\% CI 3.29-54.72, $P<.001$ ), and longer time from injury to admission was associated with decreased odds of mortality (OR 0.66, 95\% CI $0.48-0.85, P=.006$ ).

Conclusions: Those most likely to undergo surgery had $\mathrm{C} 4-\mathrm{C} 7$ injuries and incomplete spinal cord injuries. The odds of mortality increased with complete spinal cord injuries and shorter time from injury to admission, probably due to more severely injured patients dying early within 24-48 hours of injury. Thus, patients living long enough to present to the hospital may represent a self-selecting population of more stable patients. These results underscore the severity and uniqueness of CST in a less-resourced setting.
\end{abstract}

Level of Evidence: 4.

Cervical Spine

Keywords: cervical spine trauma, traumatic spinal cord injury, East Africa, global neurosurgery

\section{INTRODUCTION}

Spinal trauma, comprising fractures to the spinal column and spinal cord injury (SCI), represents a significant challenge for patients, clinicians, and healthcare systems worldwide. While the annual incidence of traumatic spinal injuries is approximately 45-80 cases per millions worldwide, low- and middle-income countries (LMICs) experience up to 130 cases per million. ${ }^{1-3}$ Additional reports confirm rates of spinal trauma are 1.6 times higher in LMICs than high-income countries. ${ }^{1,4}$
The sensorimotor and autonomic nervous system dysfunction following spinal trauma results in lifelong disability and long-term healthcare challenges. ${ }^{4-10}$ In Sub-Saharan Africa, acute mortality from spinal trauma ranges from $18 \%$ to $25 \%,{ }^{4,5}$ compared to near zero in developed nations. ${ }^{6}$ Spinal trauma leads to considerable financial strain for patients, families, and society at large due to direct medical costs and lost wages. This high socioeconomic burden is further heightened in the LMICs, where some nations spend over \$2 billion annually, including $\$ 5$ million per case of paraplegia and $\$ 9.5$ 
million per case of quadriplegia..$^{8,11-15}$ Without adequate rehabilitation services in most LMICs, patients rely heavily on family members for care.

Cervical spine trauma (CST) represents the most severe form of spinal trauma, with increased rates of morbidity and mortality compared to thoracic and lumbar injuries. ${ }^{16}$ Damage to the cervical spinal cord results in all the same sequelae as thoracic and lumbar SCI, along with upper extremity weakness and respiratory impairment due to diaphragm and upper intercostal muscle dysfunction. Over $40 \%$ of CST patients present initially with complete SCI, while the remaining present with an incomplete injury $(40 \%)$ or no cord injury $(20 \%) .{ }^{17} \mathrm{CST}$ occurs in $2 \%$ to $10 \%$ of all polytrauma patients. $^{18}$

CST presents additional challenges given the added expertise and risk involved in surgical intervention. Various studies have reported the scarcity of trained surgeons, adept surgical teams, and surgical resources in LMICs. ${ }^{19,20}$ Neurosurgery is tertiary and expensive, leaving operative resources scarce throughout less-resourced countries. ${ }^{19,21,22}$ Many LMIC regions report low rates of operative treatment for CST due to lack of equipment and implants. ${ }^{4,23,24}$

Given the devastating effects of CST in lessresourced environments, an epidemiologic investigation is needed to better understand this patient population. In a population of CST patients from a major East Africa referral center, our objectives were to $(a)$ describe the presentation and operative treatment patterns, $(b)$ report predictors of neurologic improvement, and $(c)$ assess predictors of mortality.

\section{METHODS}

\section{Study Design and Clinical Setting}

A retrospective analysis of prospectively collected data from the Muhimbili Orthopaedic Institute (MOI), a tertiary referral hospital in Dar es Salaam, Tanzania, was conducted. MOI houses approximately 120 general ward beds. At the time of data collection, the hospital housed 8 intensive care unit (ICU) beds, but has since grown to 18 ICU beds with 18 high-dependency unit surgical step-down beds. Local institutional review board approved the current study and informed consent was obtained from all patients.

\section{Patient Identification}

All patients who presented with CST from October 2016 to June 2019 (33 months) were included. CST was operationally defined as any injury to the spinal column involving the occiput to C7-T1 disc space, with or without evidence of SCI. Exclusion criteria included patients with the following conditions: only thoracic/lumbar injuries, $<14$ years old, concomitant brain injury, or underwent an operation $>4$ months from the time of injury. This case series represents an extension of a previously published cohort. ${ }^{17,21}$

\section{Clinical and Operative Data}

Several demographic and injury-specific data points were collected, including age, sex, and mechanism of injury. Injury levels were categorized according to prior studies and described per cervical level. ${ }^{25}$ Insurance status was classified as public (required to provide all funds prior to receiving hospital services) or private (no additional funds required to receive hospital services).

Fracture type was defined descriptively using a combination of prior cervical spine fracture classification schemes. ${ }^{26-29}$ Unilateral facet dislocations were defined as listhesis of $25 \%$ or less, bilateral facet dislocations had listhesis of $25 \%-75 \%$, and spondyloptosis had listhesis of $\geq 100 \% .^{21}$ Central cord syndrome was defined according to prior studies and by radiographic and/or clinical presence of a cervical SCI without ongoing compression, which most often occurred in the setting of preexisting spondylosis and canal narrowing. ${ }^{30,31}$ We acknowledge that the definition of central cord syndrome is controversial, and any spondylosis with active compression due to a fracture, disc prolapse, ligamentum flavum buckling, or facet arthropathy, was not defined as central cord syndrome. Neurologic exams were obtained upon admission and discharge according to the American Spinal Injury Association (ASIA) Impairment Scale. ${ }^{32}$ In-hospital mortality was recorded for all patients.

One of four operations was performed: (1) anterior cervical discectomy and fusion with tricortical iliac crest autograft and plate, (2) anterior cervical corpectomy with tricortical iliac crest autograft and plate, (3) posterior cervical laminectomy and fusion with lateral mass screws and rods (PCLF), and (4) posterior cervical laminectomy 
only. Tricortical iliac crest autograft was used for bone graft in anterior cases, whereas local autograft was used for posterior cases. Decompression was performed at the site of active cord compression. Time in days was recorded during the following points: injury to admission, admission to operating room, operating room to discharge, and total length of stay.

\section{Surgical Indication}

All patients were retrospectively reviewed to determine whether an indication for surgery was present using a combination of the $\mathrm{AO}$ fracture classification system ${ }^{26}$ and neurologic function, in accordance with prior studies. ${ }^{30}$ Fracture type was defined using the AO Classification System (A0-4, B1-3, C) ${ }^{26}$ Patients with traumatic disk herniation or central cord syndrome without a fracture were classified as A0. An injury was considered to have a surgical indication in one of two ways: (1) it was an unstable fracture, classified as type A4, B, or C, which required stabilization regardless of neurologic injury or (2) it was a potentially unstable fracture, classified as A0-A3, with neurologic impairment (ASIA A-D). Given the limited resources, some patients only had x-rays available due to cost, and in these cases, a best estimation of fracture type was made. All surgical indication determinations were performed by 2 individuals: a neurosurgery trainee and fellowship-trained neurosurgeon.

\section{Statistical Methods}

All continuous data were presented as mean (SD) and/or median with interquartile range (IQR) and/ or full range, whereas all count data were presented as $\mathrm{n}(\%) . T$-tests and $\chi^{2}$ tests or the Fisher exact test were used to assess differences among continuous and categorical variables, respectively. Univariate followed by multivariate logistic regression was used to assess predictors of 3 outcomes: operative treatment, improvement in neurologic function, and mortality. Any variable with $P<.10$ after univariate regression was included in the multivariate model. The second outcome of improved neurologic function was subdivided into surgical group. Significance was considered at an $\alpha$ of $<.05$. All statistical analyses were performed in RStudio, version 1.2.5033.

\section{RESULTS}

\section{Patient Cohort}

Of 101 patients presenting to MOI with CST, 25 $(24.8 \%)$ were treated operatively on a median (IQR) of postadmission day 16.0 (7.0-25.0) (Table 1). Motor vehicle and motorcycle collisions were the most common injury mechanism in both groups, and the majority of patients had public insurance $(88.1 \%)$. Almost all patients were admitted to an outside hospital before MOI $(96.0 \%)$, leading to a median (IQR) time from injury to MOI admission of 2.0 (1.0-5.0) days. Nonoperative patients received $\mathrm{x}$-rays more often, whereas operative patients more commonly received computed tomography (CT) and magnetic resonance imaging scans. Of the nonoperative cohort, $93.4 \%$ had an indication for surgery, signifying the severity of injury in this population. Twenty-six patients $(25.7 \%)$ died, with $3(12.0 \%)$ in the operative cohort and $23(30.3 \%)$ in the nonoperative cohort. The most common fracture pattern was bilateral facet dislocation $(n=27$, $26.7 \%$ of patients) followed by unilateral facet dislocation ( $\mathrm{n}=22,21.8 \%$ of patients) and burst/ teardrop fracture $(\mathrm{n}=20,19.8 \%$ of patients) (Figure $1)$.

\section{Operative Treatment}

Though $95.0 \%$ of all CST patients had an indication for surgery, 25 patients $(24.8 \%$ of total sample; $26.0 \%$ of those with an operative indication) went to surgery, which means 71 patients (74.0\% of those with an operative indication) did not undergo surgery. Of the 25 operative patients, PCLF was the most common operation (48\%), followed by anterior cervical corpectomy (28\%) (Table 2). A representative case of a C5 burst fracture and anterior cervical corpectomy with iliac crest autograft is shown Figure 2A-E). Median time from admission to operating room was 16.0 days (0 74). Postoperative imaging was obtained in only $56 \%$ of patients, likely due to cost, and was almost exclusively $\mathrm{x}$-rays. Two independent predictors of undergoing operative treatment emerged after multivariate logistic regression: (1) having an injury at C4-C7 compared to higher occiput-C3 levels (odds ratio [OR] 6.36, 95\% confidence interval [CI] $1.71-$ $32.28, P=.011)$ and (2) having an incomplete injury (ASIA B-D) compared to complete or intact (ASIA A/E) (OR 3.64; 95\% CI 1.19-12.25; $P=.029)$ (Table $3)$. Thus, it appears those most likely to undergo 
Table 1. Demographics, injury, and hospitalization information of patients with cervical spine injuries.

\begin{tabular}{|c|c|c|c|c|}
\hline & $\begin{array}{c}\text { Total } \\
\mathrm{N}=101\end{array}$ & $\begin{array}{l}\text { Operative } \\
\mathrm{N}=\mathbf{2 5}\end{array}$ & $\begin{array}{l}\text { Nonoperative } \\
\qquad \mathbf{N}=76 \\
\end{array}$ & $P$-value \\
\hline Age, mean (SD), y & $35.1(12.3)$ & $35.6(12.9)$ & $34.9(12.1)$ & .816 \\
\hline Male, n $(\%)$ & $88(87.1)$ & $22(88)$ & $66(86.8)$ & 1.000 \\
\hline Insurance, n (\%) & & & & .706 \\
\hline Public & $89(88.1)$ & $21(84.0)$ & $68(89.5)$ & \\
\hline Private & $12(11.9)$ & $4(16.0)$ & $8(10.5)$ & \\
\hline Mechanism, n (\%) & & & & .395 \\
\hline $\mathrm{MVC} / \mathrm{MCC}$ & $46(45.5)$ & $14(56.0)$ & $32(42.1)$ & \\
\hline Pedestrian & $11(10.9)$ & $1(4.0)$ & $10(13.2)$ & \\
\hline Fall & $29(28.7)$ & $7(28.0)$ & $22(28.9)$ & \\
\hline Blunt object & $10(9.9)$ & $2(8.0)$ & $8(10.5)$ & \\
\hline Other & $5(5.0)$ & $1(4.0)$ & $4(5.3)$ & \\
\hline Admitted to OSH, n (\%) & $97(96.0)$ & $22(88.0)$ & $75(98.7)$ & .074 \\
\hline \multicolumn{5}{|l|}{ Location, $\mathrm{n}(\%)^{\mathrm{a}}$} \\
\hline Occiput-C2 & $12(12.1)$ & $1(4.0)$ & $11(14.9)$ & .148 \\
\hline $\mathrm{C} 3-4$ & $16(16.2)$ & $2(8.0)$ & $14(18.9)$ & .200 \\
\hline $\mathrm{C} 4-5$ & $19(19.2)$ & $3(12.0)$ & $16(21.6)$ & .291 \\
\hline $\mathrm{C} 5-6$ & $28(28.3)$ & $8(32.0)$ & $20(27.0)$ & .620 \\
\hline C6-7 & $20(20.2)$ & $10(40.0)$ & $10(13.5)$ & .004 \\
\hline C7-T1 & $4(4.0)$ & $1(4.0)$ & $3(4.1)$ & .930 \\
\hline \multicolumn{5}{|l|}{ Imaging, $\mathrm{n}(\%)$} \\
\hline X-ray & $82(81.2)$ & $16(64.0)$ & $66(86.8)$ & .025 \\
\hline $\mathrm{CT}$ & $32(31.7)$ & $10(40.0)$ & $22(28.9)$ & .434 \\
\hline MRI & $70(69.3)$ & $18(72.0)$ & $52(68.4)$ & .931 \\
\hline \multicolumn{5}{|l|}{ Neurologic status, n (\%) } \\
\hline Complete (ASIA A) & $52(51.5)$ & $10(48.4)$ & $42(55.3)$ & .274 \\
\hline Incomplete (ASIA B-D) & 39 (38.6) & $14(48.4)$ & 25 (32.9) & .069 \\
\hline Intact (ASIA E) & $10(9.9)$ & $1(3.2)$ & $9(11.8)$ & .452 \\
\hline Indication for surgery, n (\%) & $96(95.0)$ & $25(100)$ & $71(93.4)$ & .433 \\
\hline Central cord, n (\%) & $12(11.9)$ & $1(4.0)$ & $11(14.5)$ & .295 \\
\hline SBP low $(\mathrm{n}=22)$, median (range) & $100.5(50.0-128.0)$ & $103.0(97.0-125.0)$ & $100.0(50.0-128.0)$ & .483 \\
\hline Days in ICU $(\mathrm{n}=21)$, median (range) & $3(1-27)$ & $4(3-27)$ & $2(1-15)$ & .070 \\
\hline Length of stay, mean (SD), days & $27.4(21.4)$ & $34.4(19.4)$ & $25.1(21.6)$ & .063 \\
\hline Pressure ulcer, n (\%) & $15(14.9)$ & $4(16.0)$ & $11(14.5)$ & 1.000 \\
\hline Mortality, n (\%) & $26(25.7)$ & $3(12.0)$ & $23(30.3)$ & .122 \\
\hline
\end{tabular}

Abbreviations: CT, computed tomography; ICU, intensive care unit; MRI, magnetic resonance imaging; MVC/MCC, motor vehicle or motorcycle collision; OSH, outside hospital, SBP, systolic blood pressure.

${ }^{\mathrm{a}}$ Two patients had central cord syndrome without MRI, and a specific injury level could not be assigned.

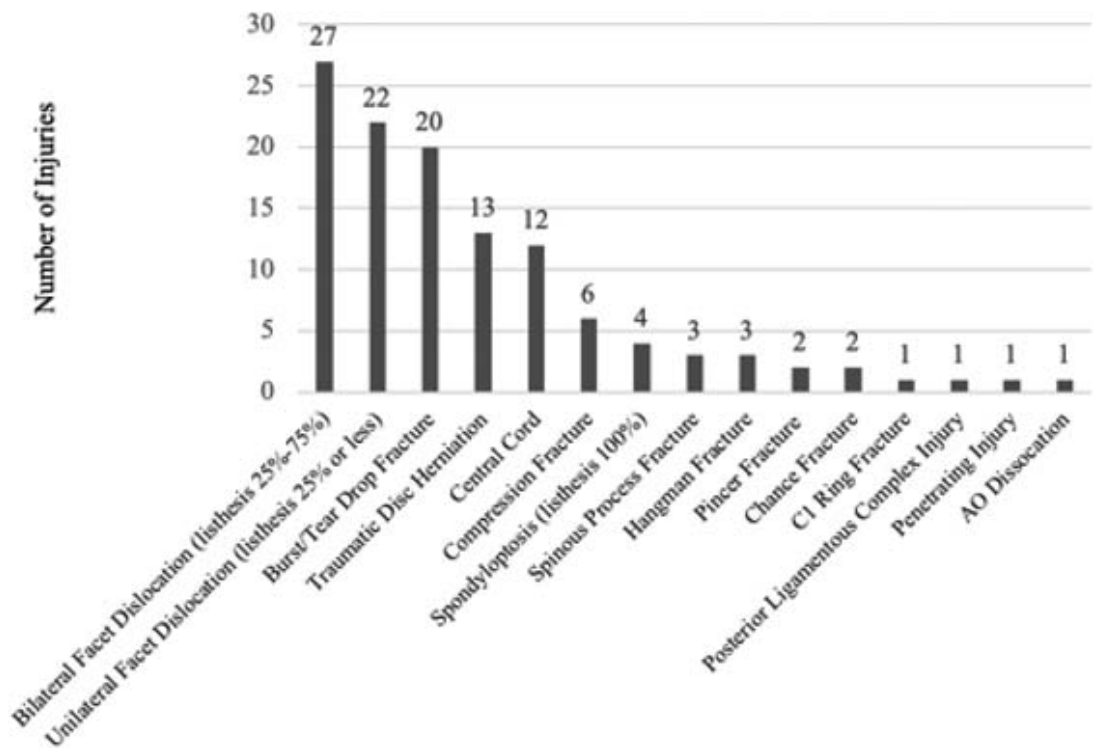

Figure 1. Fracture types among 101 cervical spine trauma patients (each fracture type counted separately when more than 1 injury was present). 
Table 2. Operative details of those undergoing surgery.

\begin{tabular}{lc}
\hline Parameter & Value (n = 25) \\
\hline Operation, n (\%) & \\
Anterior cervical discectomy and fusion with plate & $4(16)$ \\
Anterior cervical corpectomy with plate & $7(28)$ \\
Posterior cervical laminectomy fusion & $12(48)$ \\
Posterior cervical laminectomy only & $2(8)$ \\
Levels fused, mean (SD) & $1.78(0.52)$ \\
Screws, mean (SD) & \\
Anterior & $4.68(0.95)$ \\
Posterior & $4.90(1.00)$ \\
Postoperative imaging, n (\%) & $13(52)$ \\
X-ray & $1(4)$ \\
CT & $0(0)$ \\
MRI & \\
\hline
\end{tabular}

Abbreviations: CT, computed tomography; MRI, magnetic resonance imaging.

surgery were patients with lower cervical injuries (C4-C7) and incomplete SCI injuries (Figure 3).

\section{Neurologic Outcomes}

In the 76 patients with an exam recorded at discharge $(75.2 \%), 12$ patients $(15.8 \%)$ improved neurologically by at least 1 ASIA grade (Tables 4 and 5). After univariate logistic regression in all patients (operative and nonoperative), the only factor associated with neurological improvement was having an incomplete SCI (ASIA B-D) (OR $4.38,95 \%$ CI $1.18-21.20, P=.038)$; however, this lost statistical significance after multivariate analysis (Table 6). In the smaller subset of 22 patients who underwent surgery, univariate logistic regression showed a trend toward faster time to surgery being associated with an increased odds of neurologic improvement (OR 1.08, 95\% CI 1.02-1.21, $P=$ .061 ), but this too lost significance after multivariate analysis. Importantly, operative treatment was not associated with neurologic improvement on univariate testing (OR $0.79,95 \%$ CI $0.16-2.99, P=.743$ ).

\section{Mortality}

A total of 26 patients died $(25.7 \%)$, with 3 $(12.0 \%)$ in the operative group and $23(30.3 \%)$ in the nonoperative group. After multivariate testing, 2 factors were significantly associated with increased odds of mortality (Table 7). Counterintuitively, a longer time from injury to MOI admission was associated with a $34 \%$ decreased odds of mortality (OR $0.66,95 \%$ CI $0.48-0.85, P=.006$ ). Said in other words, a faster time from injury to MOI admission was associated with increased odds of death. Additionally, having a complete injury (ASIA A) was associated with over 11 times the odds of mortality compared to incomplete or intact patient status (ASIA B-E) (OR 11.75, 95\% CI 3.29-

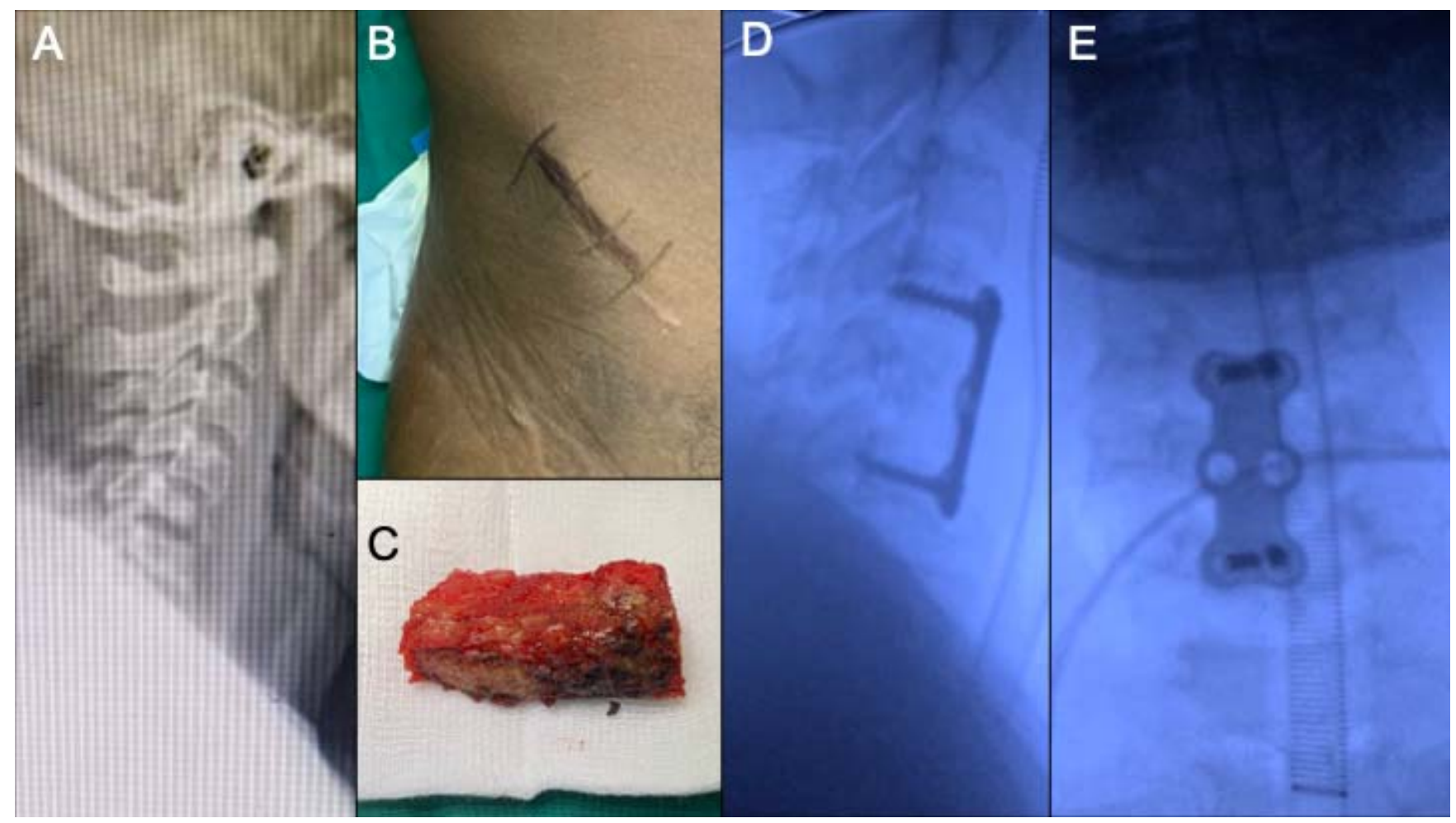

Figure 2A-E. (A) Patient with C5 burst fracture. (B) Incision over right anterior iliac crest in preparation for (C) tricortical iliac crest autograft. (D, E) postoperative xrays. 
Table 3. Predictors of operative treatment. Multivariate logistic regression controlled for age, sex, and mechanism of injury.

\begin{tabular}{|c|c|c|c|c|}
\hline \multirow[b]{2}{*}{ Variable } & \multicolumn{2}{|c|}{ Univariate Logistic Regression } & \multicolumn{2}{|c|}{ Multivariate Logistic Regression } \\
\hline & OR $(95 \% \mathrm{CI})$ & $P$ & OR $(95 \% \mathrm{CI})$ & $P$ \\
\hline Age & & .966 & & $\ldots$ \\
\hline Young, $<30(\mathrm{n}=36)$ & reference & & $\ldots$ & \\
\hline Old, $\geq 30(\mathrm{n}=65)$ & $0.98(0.39-2.59)$ & & & \\
\hline Sex & & .881 & & $\ldots$ \\
\hline Female $(\mathrm{n}=13)$ & reference & & $\ldots$ & \\
\hline Male $(\mathrm{n}=88)$ & $1.11(0.31-5.28)$ & & & \\
\hline Injury level & & & & .011 \\
\hline Occiput-C3 $(\mathrm{n}=28)$ & reference & .046 & $6.36(1.71-32.28)$ & \\
\hline $\mathrm{C} 4-\mathrm{C} 7(\mathrm{n}=71)$ & $3.74(1.15-16.87)$ & & & \\
\hline Insurance & & .466 & & $\ldots$ \\
\hline Private $(\mathrm{n}=12)$ & reference & & $\ldots$ & \\
\hline Public $(\mathrm{n}=89)$ & $0.62(0.18-2.50)$ & & & \\
\hline \multicolumn{5}{|l|}{ Neurologic exam } \\
\hline Complete: ASIA A (ref) versus B-E; $(\mathrm{n}=52)$ & $0.54(0.21-1.34)$ & .188 & & \\
\hline Incomplete: ASIA B-D (ref) versus A/E; $(\mathrm{n}=39)$ & $2.60(1.04-6.67)$ & .043 & $3.64(1.19-12.55)$ & .029 \\
\hline Intact: ASIA E (ref) versus A-D; $(\mathrm{n}=10)$ & $0.31(0.02-1.78)$ & .279 & $\ldots$ & $\ldots$ \\
\hline
\end{tabular}

54.72, $P<.001)$. Though a trend for nonoperative treatment associated with increased odds of mortality was seen, statistical significance was not achieved (OR 36.7, 95\% CI 0.87-20.35, $P=.097$ ).

\section{DISCUSSION}

Suffering a traumatic CST is a life-changing event in any part of the world, yet the ramifications are felt especially hard in LMICs. The current study described patterns of presentation, operative treatment, neurologic improvement, and mortality after CST from a large East Africa referral center. Though 96 patients $(95.0 \%)$ of patients had an indication for surgery, only 25 patients $(24.7 \%)$ underwent surgical treatment at a median of 16 days postadmission. PCLF with lateral mass screws and rods and anterior cervical corpectomy with tricortical iliac crest autograft and plate were the most common operations performed. Those with $\mathrm{C} 4-\mathrm{C} 7$ injuries and incomplete SCI were most likely to undergo surgery. Neurologic improvement rates were low at $15.8 \%$, and mortality occurred in $25.7 \%$ of patients. Those with complete SCI were associated with significantly increased odds of death. Surprisingly, a longer time from injury to admission conferred a decreased risk of death. Overall, these results reinforce the uniqueness of CST care in less-resourced settings and emphasize the importance of an individualized approach to spine trauma care in LMICs.

\section{Rates of Operative Treatment by Cervical Level}

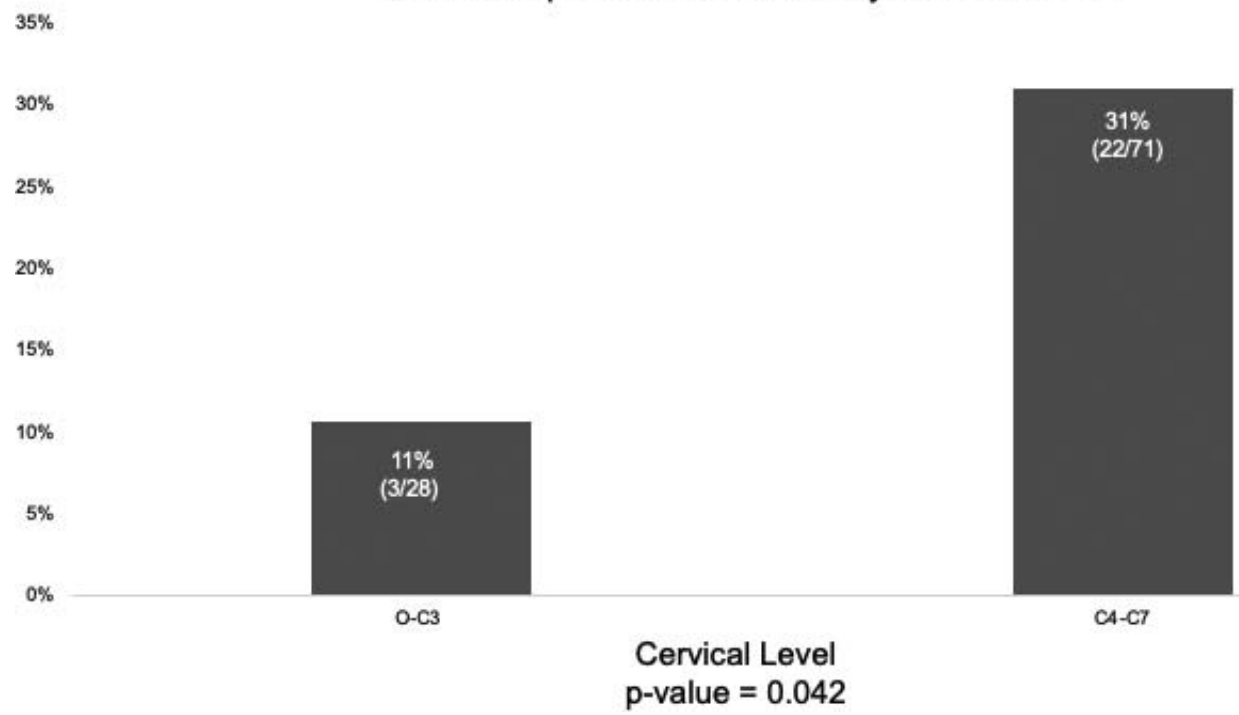

Figure 3. Rates of operative treatment by cervical level and neurologic exam. 


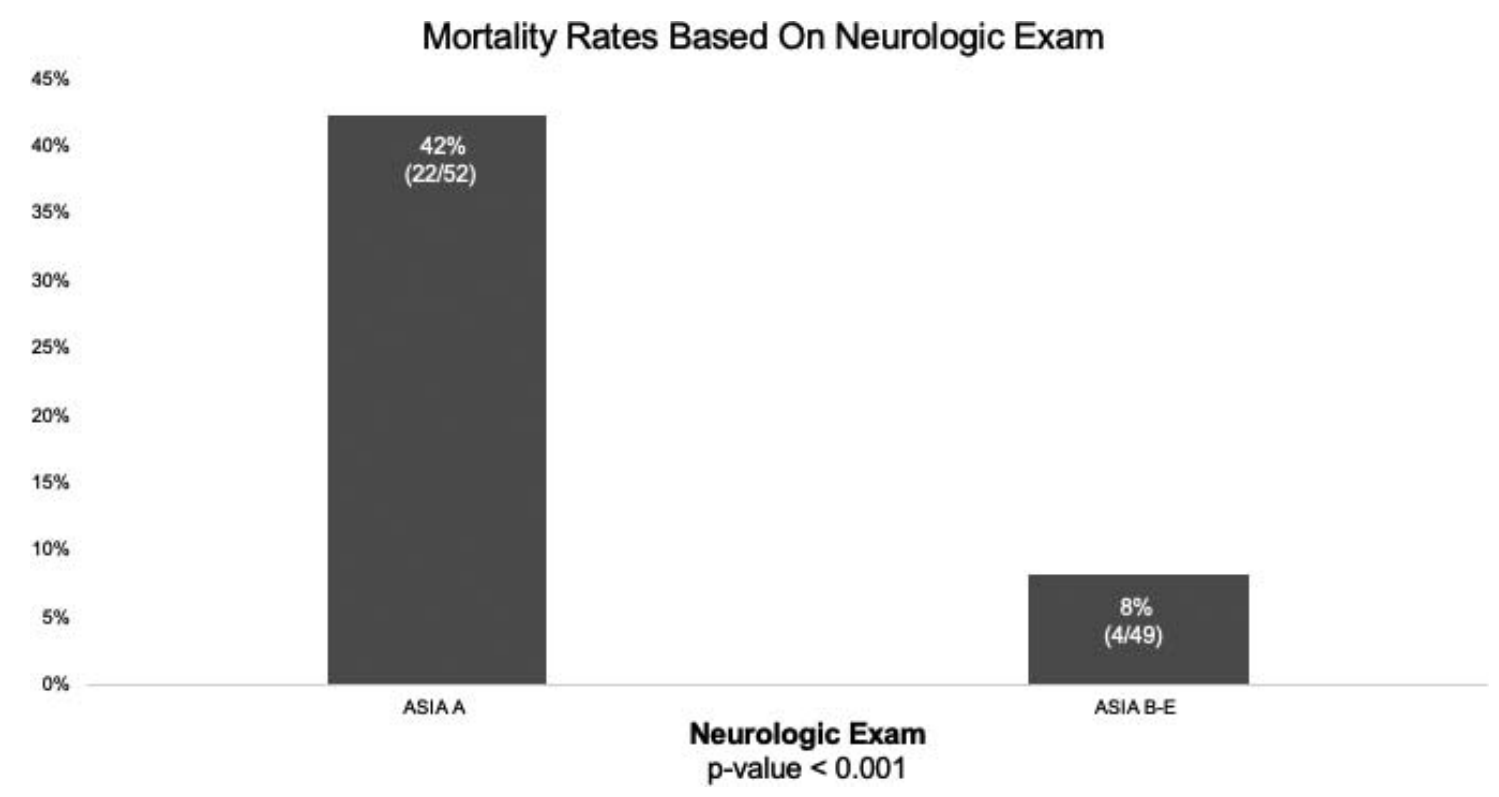

Figure 4. Mortality rates based on neurologic exam and treatment.

\section{Current Patterns of Operative Treatment}

The most common fracture pattern was bilateral facet dislocation, followed by unilateral facet dislocation and burst fracture, which fits exactly with the 3 most common injuries in a study of CST patients from South Africa. ${ }^{20}$ We also reported a $24.8 \%$ operative rate, which is slightly less than a previous published rate of $38.4 \%$ in 125 CST patients from Ghana. ${ }^{33}$ While nearly all patients $(95 \%)$ had an indication for surgery, unfortunately, our low operative rate is common in LMICs, where many patients don't undergo surgery due to insufficient funds or lack of equipment, including spinal implants, operating beds, and surgical tools. PCLF was the most common approach in our study, followed by anterior cervical corpectomy with tricortical iliac crest autograft. In Cambodia, Choi et $\mathrm{al}^{25}$ operated on 20 cervical trauma patients and performed anterior cervical discectomy and fusion most commonly, followed by posterior fusion with wiring, yet only a single corpectomy was

Table 4. Changes in ASIA score from admission to discharge, $\mathrm{N}=76$.

\begin{tabular}{|c|c|c|c|c|c|c|}
\hline \multirow[t]{2}{*}{$\begin{array}{l}\text { ASIA on } \\
\text { Admission }\end{array}$} & \multicolumn{6}{|c|}{ n $(\%)$} \\
\hline & $30(39)$ & $11(15)$ & $11(15)$ & $11(15)$ & $13(17)$ & $76(100)$ \\
\hline $\mathrm{E}$ & 0 & 0 & 0 & 0 & 10 & $10(13)$ \\
\hline $\mathrm{D}$ & 0 & 0 & 0 & 8 & 2 & $10(13)$ \\
\hline $\mathrm{C}$ & 0 & 1 & 7 & 3 & 1 & $12(16)$ \\
\hline $\mathrm{B}$ & 2 & 8 & 3 & 0 & 0 & $13(17)$ \\
\hline \multirow[t]{3}{*}{ A } & 28 & 2 & 1 & 0 & 0 & $31(40)$ \\
\hline & A & $\mathrm{B}$ & $\mathrm{C}$ & $\mathrm{D}$ & $\mathrm{E}$ & Total \\
\hline & \multicolumn{6}{|c|}{ ASIA on Discharge } \\
\hline
\end{tabular}

required. Our high rate of corpectomies may be attributed to burst fractures being the third most common fracture pattern seen, where the entire vertebral body must be removed to adequately decompress the spinal canal. Tricortical iliac crest autograft was used in all cases, an affordable and convenient source of bone graft. ${ }^{34}$ In addition, lower-cervical injuries were more commonly operated on than higher-cervical injuries, a trend found in earlier studies. ${ }^{30}$ Explanations for this finding are likely multifactorial and may be due to high cervical injuries leading to quadriplegia and a poor prognosis. Another reason is that craniocervical injuries require more complex operations to stabilize and treat. Instrumentation of the occiput, $\mathrm{C} 1$, and $\mathrm{C} 2$ are higher risk, and surgeons may lack either the experience or necessary equipment to safely perform these operations. Lastly, incomplete injuries were taken to surgery more often than complete injuries, a testament to a resource limited setting, which likely represents allotment of resources to those most likely to improve.

\section{Neurologic Improvement}

The neurologic improvement rate was low at $15.8 \%$, likely due to long delays from admission to

Table 5. Categorization of ASIA score changes in those who survived.

\begin{tabular}{lccr}
\hline & Worsened & Stable & Improved \\
\hline Operative $(\mathrm{n}=22), \mathrm{n}(\%)$ & $1(4.5)$ & $18(81.8)$ & $3(13.6)$ \\
Nonoperative $(\mathrm{n}=54), \mathrm{n}(\%)$ & $3(5.6)$ & $42(77.7)$ & $9(16.7)$ \\
Total $(\mathrm{n}=76), \mathrm{n}(\%)$ & $4(5.3)$ & $60(78.9)$ & $12(15.8)$
\end{tabular}


Table 6. Predictors of neurologic improvement among all patients and among operative patients. Multivariate logistic regression controlled for age, sex, admission neurologic exam, and level of injury.

\begin{tabular}{|c|c|c|c|c|}
\hline \multirow[b]{2}{*}{ Variable } & \multicolumn{2}{|c|}{ Univariate Logistic Regression } & \multicolumn{2}{|c|}{ Multivariate Logistic Regression } \\
\hline & OR $(95 \% \mathrm{CI})$ & $P$ & OR $(95 \% \mathrm{CI})$ & $P$ \\
\hline \multicolumn{5}{|l|}{ Among all patients, $\mathrm{N}=76$} \\
\hline Age & & .483 & $\ldots$ & $\ldots$ \\
\hline Old, $\geq 30(\mathrm{n}=51)$ & reference & & & \\
\hline Young, $<30(\mathrm{n}=25)$ & $0.64(0.18,2.38)$ & & & \\
\hline Sex & & .595 & $\ldots$ & $\ldots$ \\
\hline Female $(\mathrm{n}=10)$ & reference & & & \\
\hline Male $(\mathrm{n}=66)$ & $1.80(0.29,34.91)$ & & & \\
\hline Injury level & & .603 & $\ldots$ & $\ldots$ \\
\hline Occiput-C3 (n = 22) & reference & & & \\
\hline $\mathrm{C} 4-\mathrm{C} 7(\mathrm{n}=52)$ & $0.70(0.19,2.94)$ & & & \\
\hline Insurance & & .14 & $\ldots$ & $\ldots$ \\
\hline Private $(\mathrm{n}=9)$ & reference & & & \\
\hline Public $(\mathrm{n}=67)$ & $0.31(0.68,1.67)$ & & & \\
\hline \multicolumn{5}{|l|}{ Time from injury to admission } \\
\hline Continuous (days) & $1.00(0.94,1.03)$ & .954 & & \\
\hline Operative & & .743 & $\ldots$ & $\ldots$ \\
\hline Nonoperative $(\mathrm{n}=54)$ & reference & & & \\
\hline Operative $(\mathrm{n}=22)$ & $0.79(0.16,2.99)$ & & & \\
\hline Admission neurologic exam & & .234 & $\ldots$ & $\ldots$ \\
\hline Complete (ASIA A) $(\mathrm{n}=31)$ & $0.43(0.09,1.59)$ & & & \\
\hline Incomplete (ASIA B-D) $(\mathrm{n}=35)$ & $4.38(1.18,21.20)$ & .038 & $4.14(1.01,21.64)$ & .061 \\
\hline \multicolumn{5}{|l|}{ Operative patients, $\mathrm{N}=22$} \\
\hline Age & & .907 & $\ldots$ & $\ldots$ \\
\hline Young, $<30(\mathrm{n}=8)$ & reference & & & \\
\hline Old, $\geq 30(\mathrm{n}=14)$ & $1.17(0.09,27.83)$ & & & \\
\hline Sex & & .313 & $\ldots$ & $\ldots$ \\
\hline Female $(\mathrm{n}=3)$ & reference & & & \\
\hline Male $(\mathrm{n}=19)$ & $0.24(0.01,6.37)$ & & & \\
\hline Injury level & & .313 & $\ldots$ & $\ldots$ \\
\hline Occiput-C3 (n=3) & reference & & & \\
\hline $\mathrm{C} 4-\mathrm{C} 7(\mathrm{n}=19)$ & $0.24(0.01,6.37)$ & & & \\
\hline Time from admission to operating room, continuous (days) & $1.08(1.01,1.21)$ & .061 & $1.10(0.98,1.30)$ & .169 \\
\hline
\end{tabular}

surgery. An earlier CST series from India ${ }^{34}$ reported a mean neurologic recovery by 1.1 ASIA grades, and their high rate of neurologic improvement may be due to a mean operative day of 7 days postadmission, compared to our median of 16 days post- admission. In high-income countries, where hospital resources and adequate ICU care are ubiquitous, it is well established that faster time to decompression is associated with improved neurologic outcomes. ${ }^{35-37}$ However, in an LMIC setting, it appears that faster

Table 7. Predictors of mortality among all patients $(N=101)$. Multivariate logistic regression controlled for age, sex, and mechanism of injury.

\begin{tabular}{|c|c|c|c|c|}
\hline \multirow[b]{2}{*}{ Variable } & \multicolumn{2}{|c|}{ Univariate Logistic Regression } & \multicolumn{2}{|c|}{ Multivariate Logistic Regression } \\
\hline & OR (95\% CI) & $P$ & OR $(95 \%$ CI $)$ & $P$ \\
\hline Age & & .412 & $\ldots$ & $\ldots$ \\
\hline Young, $<30(\mathrm{n}=36)$ & reference & & & \\
\hline Old, $\geq 30(\mathrm{n}=65)$ & $0.68(0.27,1.73)$ & & & \\
\hline Sex & & .814 & $\ldots$ & $\ldots$ \\
\hline Female $(\mathrm{n}=13)$ & reference & & & \\
\hline Male $(\mathrm{n}=88)$ & $1.18(0.33,5.60)$ & & & \\
\hline Injury level & & .858 & $\ldots$ & $\ldots$ \\
\hline Occiput-C3 $(\mathrm{n}=28)$ & reference & & & \\
\hline $\mathrm{C} 4-\mathrm{C} 7(\mathrm{n}=71)$ & $1.10(0.41,3.15)$ & & & \\
\hline Insurance & & .95 & $\ldots$ & $\ldots$ \\
\hline Public $(\mathrm{n}=89)$ & reference & & & \\
\hline Private $(\mathrm{n}=12)$ & $1.05(0.28,5.01)$ & & & \\
\hline Time from injury to admission, continuous (days) & $0.75(0.57,0.91)$ & .013 & $0.66(0.48,0.85)$ & .006 \\
\hline Admission neurologic exam & & $<.001$ & $11.75(3.29,54.72)$ & $<.001$ \\
\hline ASIA B-E $(n=49)$ & reference & & & \\
\hline ASIA A $(n=52)$ & $8.25(2.82,30.37)$ & & & \\
\hline Nonoperative & & .081 & $3.67(0.87,20.35)$ & .097 \\
\hline Operative $(\mathrm{n}=25)$ & reference & & & \\
\hline Nonoperative $(\mathrm{n}=76)$ & $3.18(0.98,14.38)$ & & & \\
\hline
\end{tabular}


time to surgery may not offer any benefit without adequate perioperative and ICU services. CST patients require complex postoperative ICU care, including hourly airway and blood pressure monitoring, inotropes to keep the spinal cord perfused, and experienced nursing care. The importance of adequate ICU care cannot be overstated.

\section{Mortality}

Mortality rates after CST range from $27.2 \%$ in northeast Tanzania ${ }^{4}$ to $30 \%$ in rural India, ${ }^{38}$ which are similar to our rate of $25.7 \%$. Additionally, one Nigerian series reported $72 \%$ of all spine trauma deaths occurred from cervical injuries. ${ }^{5}$ We found that having a complete SCI was associated with over an 11-fold increase in odds of death compared to incomplete SCI. In addition, nonoperative treatment was not associated with an increased risk of mortality, which conflicts with prior literature that nonoperative treatment after any spine trauma was associated with a 7.4-fold increase in odds of death. ${ }^{30}$ This finding may speak to the smaller sample studied, the severity of CST patients, or the higher risk of cervical spine operations.

Perhaps the most counterintuitive finding in our study was that a longer time from injury to admission was associated with decreased odds of mortality, which conflicts with the aforementioned notion that earlier treatment leads to better outcomes. Previous reports of LMIC spine trauma patients have noted a median time from injury to hospital admission of 48 hours. ${ }^{21}$ Thus, it is possible that in the critical 24-48 hours after CST, the more severely injured patients not yet at the hospital may quickly lose vital respiratory or autonomic function and die. Thus, those that survive the early time period may represent a self-selecting, stable group of patients that have passed the critical window of vulnerability. Of note, one complicating factor is that almost all patients $(96 \%)$ were admitted from some form of an outside healthcare facility, and no information can be gleaned as to the type of care provided in this triage setting.

Equally important aspects of treating CST patients are ICU care and rehabilitation services. Many LMICs lack critical care beds and appropriately trained personnel to manage complex CST patients before and after surgery. It is possible that improvements in critical care provisions may result in reduced mortality but may increase the survival of those with greater neurological disability. It is therefore important to consider the development of postdischarge care and rehabilitation services, such as locally produced wheelchairs and bladder training for newly incontinent patients. Overall, these data reinforce an important conclusion, that CST treatment may need to be adjusted to the resources of a given hospital setting. While earlier treatment may lead to improved neurologic outcomes in wellresourced settings with adequate ICU expertise, upto-date equipment, and experienced nursing care, the same benefit from earlier surgery may not occur in a hospital without an ICU, reliable access to inotropes, or experienced intensivists and ICU nurses.

\section{Limitations}

There are several limitations to the current study. Follow-up information was not collected, so it is unknown how nonoperative treatment impacted long-term neurologic status and radiographic healing. Also, the results may be difficult to generalize to other neurosurgery and orthopedic departments in LMICs, because each institution has a unique set of available resources that dictate operative decisionmaking. Mortality was not accounted for postdischarge, which may lead to underreporting of true mortality rates. Finally, despite use of a prospective registry, the data were analyzed retrospectively. Determination of surgical indication is a complex process, and doing this retrospectively may have led to misclassifications. Of note, due to new data collection instruments, significant data were missing for systolic blood pressure low and days in ICU.

\section{CONCLUSIONS}

In a large series of exclusively CST from a major East African referral center, $24.8 \%$ of patients underwent surgery. Those most likely to undergo surgery were patients with lower cervical injuries and incomplete SCI. The odds of mortality increased with complete SCI and, counterintuitively, decreased time from injury to admission. These results underscore the uniqueness of treating CST patients in a less-resourced setting, and how a specialized approach is needed to address cervical spine trauma in LMICs.

\section{REFERENCES}

1. Kumar R, Lim J, Mekary RA, et al. Traumatic spinal injury: global epidemiology and worldwide volume. World Neurosurg. 2018;113:e345-e363.

2. Cripps RA, Lee BB, Wing P, Weerts E, Mackay J, Brown 
D. A global map for traumatic spinal cord injury epidemiology: towards a living data repository for injury prevention. Spinal Cord. 2011;49(4):493-501.

3. van den Berg ME, Castellote JM, de Pedro-Cuesta J, Mahillo-Fernandez I. Survival after spinal cord injury: a systematic review. J Neurotrauma. 2010;27(8):1517-1528.

4. Moshi H, Sundelin G, Sahlen KG, Sorlin A. Traumatic spinal cord injury in the north-east Tanzania-describing incidence, etiology and clinical outcomes retrospectively. Glob Health Action. 2017;10(1):1355604.

5. Obalum DC, Giwa SO, Adekoya-Cole TO, Enweluzo GO. Profile of spinal injuries in Lagos, Nigeria. Spinal Cord. 2009;47(2):134-137.

6. Divanoglou A, Westgren N, Seiger A, Hulting C, Levi R. Late mortality during the first year after acute traumatic spinal cord injury: a prospective, population-based study. J Spinal Cord Med. 2010;33(2):117-127.

7. Ahn H, Singh J, Nathens A, et al. Pre-hospital care management of a potential spinal cord injured patient: a systematic review of the literature and evidence-based guidelines. J Neurotrauma. 2011;28(8):1341-1361.

8. Aleem IS, DeMarco D, Drew B, et al. The burden of spine fractures in India: a prospective multicenter study. Global Spine J. 2017;7(4):325-333.

9. Bragge P, Piccenna L, Middleton JW, et al. Developing a spinal cord injury research strategy using a structured process of evidence review and stakeholder dialogue. Part I: rapid review of SCI prioritisation literature. Spinal Cord. 2015;53(10):714-720.

10. Ackery A, Tator C, Krassioukov A. A global perspective on spinal cord injury epidemiology. J Neurotrauma. 2004;21(10):1355-1370.

11. Krause JS, Saunders LL, DeVivo MJ. Income and risk of mortality after spinal cord injury. Arch Phys Med Rehabil. 2011;92(3):339-345.

12. Mock C, Joshipura M, Arreola-Risa C, Quansah R. An estimate of the number of lives that could be saved through improvements in trauma care globally. World J Surg. 2012;36(5):959-963.

13. Spiegel DA, Gosselin RA, Coughlin RR, Joshipura M, Browner BD, Dormans JP. The burden of musculoskeletal injury in low and middle-income countries: challenges and opportunities. J Bone Joint Surg Am. 2008;90(4):915-923.

14. Winegar CD, Lawrence JP, Friel BC, et al. A systematic review of occipital cervical fusion: techniques and outcomes. $J$ Neurosurg Spine. 2010;13(1):5-16.

15. Kawu AA, Olawepo A, Salami AO, Kuranga SA, Abdulhameed S, Esenwah VC. A cost analysis of conservative management of spinal cord-injured patients in Nigeria. Spinal Cord. 2011;49(11):1134-1137.

16. Schmidt OI, Gahr RH, Gosse A, Heyde CE. ATLS(R) and damage control in spine trauma. World J Emerg Surg. 2009;4:9.

17. Leidinger A, Kim EE, Navarro-Ramirez R, et al. Spinal trauma in Tanzania: current management and outcomes. $J$ Neurosurg Spine. 2019;31(1):103-111.

18. Morris CG, Mullan B. Clearing the cervical spine after polytrauma: implementing unified management for unconscious victims in the intensive care unit. Anaesthesia. 2004;59(8):755761.

19. Budohoski KP, Ngerageza JG, Austard B, et al.
Neurosurgery in East Africa: innovations. World Neurosurg. 2018;113:436-452.

20. Fielingsdorf K, Dunn RN. Cervical spine injury outcome - a review of 101 cases treated in a tertiary referral unit. S Afr Med J. 2007;97(3):203-207.

21. Magogo JLA, Mango M, Zuckerman SL, et al. Operative treatment of traumatic spinal injuries in Tanzania: surgical management, neurologic outcomes, and time to surgery. Global Spine J. 2021;11(1):89-98.

22. Santos MM, Qureshi MM, Budohoski KP, et al. The growth of neurosurgery in East Africa: challenges. World Neurosurg. 2018;113:425-435.

23. Nilsen C, Østbye T, Daltveit AK, et al. Trends in and socio-demographic factors associated with caesarean section at a Tanzanian referral hospital, 2000 to 2013. Int J Equity Health. 2014;13(1):87.

24. Rashid SM, Jusabani MA, Mandari FN, Dekker MCJ. The characteristics of traumatic spinal cord injuries at a referral hospital in Northern Tanzania. Spinal Cord Ser Cases. 2017;3:17021.

25. Choi JH, Park PJ, Din V, Sam N, Iv V, Park KB. Epidemiology and clinical management of traumatic spine injuries at a major government hospital in Cambodia. Asian Spine J. 2017;11(6):908-916.

26. Schnake KJ, Schroeder GD, Vaccaro AR, Oner C. AOSpine classification systems (subaxial, thoracolumbar). $J$ Orthop Trauma. 2017;31(suppl 4):S14-S23.

27. Anderson PA, Moore TA, Davis KW, et al. Cervical spine injury severity score. Assessment of reliability. $J$ Bone Joint Surg Am. 2007;89(5):1057-1065.

28. Holdsworth F. Fractures, dislocations, and fracturedislocations of the spine. J Bone Joint Surg Am. 1970;52(8):1534 1551.

29. Aarabi B, Walters BC, Dhall SS, et al. Subaxial cervical spine injury classification systems. Neurosurgery. 2013;72(suppl 2):170-186.

30. Lessing NL, Lazaro A, Zuckerman SL, et al. Nonoperative treatment of traumatic spinal injuries in Tanzania: who is not undergoing surgery and why? Spinal Cord. 2020;58(11):1197-1205.

31. Lenehan B, Fisher CG, Vaccaro A, Fehlings M, Aarabi $\mathrm{B}$, Dvorak MF. The urgency of surgical decompression in acute central cord injuries with spondylosis and without instability. Spine (Phila Pa 1976). 2010;35(21 suppl):S180-S186.

32. Kirshblum SC, Waring W, Biering-Sorensen F, et al. Reference for the 2011 revision of the International Standards for Neurological Classification of Spinal Cord Injury. J Spinal Cord Med. 2011;34(6):547-554.

33. Ametefe MK, Bankah PE, Yankey KP, Akoto H, Janney D, Dakurah TK. Spinal cord and spine trauma in a large teaching hospital in Ghana. Spinal Cord. 2016;54(12):1164 1168 .

34. Ramnarain A, Govender S. Fibular allograft and anterior plating for dislocations/fractures of the cervical spine. Indian J Orthop. 2008;42(1):83-86.

35. Liu JM, Long XH, Zhou Y, Peng HW, Liu ZL, Huang $\mathrm{SH}$. Is urgent decompression superior to delayed surgery for traumatic spinal cord injury? A meta-analysis. World Neurosurg. 2016;87:124-131.

36. Fehlings MG, Vaccaro A, Wilson JR, et al. Early versus delayed decompression for traumatic cervical spinal cord 
injury: results of the Surgical Timing in Acute Spinal Cord Injury Study (STASCIS). PLoS One. 2012;7(2):e32037.

37. Wilson JR, Singh A, Craven C, et al. Early versus late surgery for traumatic spinal cord injury: the results of a prospective Canadian cohort study. Spinal Cord. 2012;50(11):840-843.

38. Chacko V, Joseph B, Mohanty SP, Jacob T. Management of spinal cord injury in a general hospital in rural India. Paraplegia. 1986;24(5):330-335.

\section{Disclosures and COI: None.}

Corresponding Author: Scott L. Zuckerman, MD, MPH, Department of Neurological Surgery,
Vanderbilt University Medical Center, Medical Center North T-4224, Nashville, TN 37212. Phone: (615) 835-7075; Fax: (615) 343-6948; Email: zuckerman.scott@gmail.com.

Published 0 Month 2021

This manuscript is generously published free of charge by ISASS, the International Society for the Advancement of Spine Surgery. Copyright (C) 2021 ISASS. To see more or order reprints or permissions, see http://ijssurgery.com. 